\title{
Using Finite Element Software For Enhancing A Vibration Analysis Curriculum
}

\author{
Cyrus K. Hagigat \\ Engineering Technology Department \\ College of Engineering \\ The University of Toledo \\ Toledo, Ohio 43606
}

\section{I: Introduction}

The theme of this article is using finite element software as a supplemental teaching tool in a vibration analysis curriculum. There are several commercially available finite element software packages. Examples of commercially available software packages are ALGOR, ANSYS and NASTRAN. The choice of the software package is influenced by a variety of technical and financial factors. The discussion of suitability of a particular software package is outside the scope of this article. In this article, using ANSYS as a supplemental teaching tool in vibration analysis is discussed.

ANSYS is a finite element software package containing extensive structural analysis capabilities. ANSYS is extensively used in rotating equipment design and analysis in aerospace and power industries. Examples of rotating equipments are jet engines and power plant pumps and turbines.

Most real world vibration analysis problems do not have a closed form mathematical solution. Before proliferation of inexpensive computer hardware and relatively inexpensive computer software, approximate solutions were used for solving most practical vibration analysis problems. These classical and approximate techniques usually involve analyzing a simpler but similar structure that has a closed form mathematical solution. Often times, expensive prototype construction and testing were necessary to check the validity and accuracy of the approximate solutions.

Using the finite element technique in solving vibration analysis problems eliminates the need for developing approximate mathematical solutions. Furthermore, using a computerized technique such as the finite element analysis enables one to obtain solutions to computationally intensive problems such as transient dynamic analyses. Using the classical techniques for solving computationally intensive problems can be time consuming and at times even impossible.

This article points out the use of finite element technique as a supplement rather than a substitute for classical vibration analysis. Included are three analyses - modal, harmonic and transient dynamic as examples of problems solved by ANSYS finite element software.

Suggestions for including the finite element analysis technique in a vibration analysis curriculum are made. 


\section{II: Mathematical Formulation of Vibrating Systems As Finite Element Models}

The general equation of motion for a single degree of freedom vibrating system with viscous damping can be expressed as shown in equation (1). ${ }^{1}$

$$
m \ddot{u}+c \dot{u}+k u=p(t)
$$

In equation (1), $m$ is the mass, $c$ is the damping coefficient and $k$ is the stiffness for the single degree of freedom vibrating system. $p(t)$ is the excitation force applied to the system as a function of time. $u, \dot{u}$ and $\ddot{u}$ are the displacement, velocity and acceleration of the single degree of freedom system respectively.

Figure 1 is an illustration of a generalized single degree of a freedom system. ${ }^{1}$

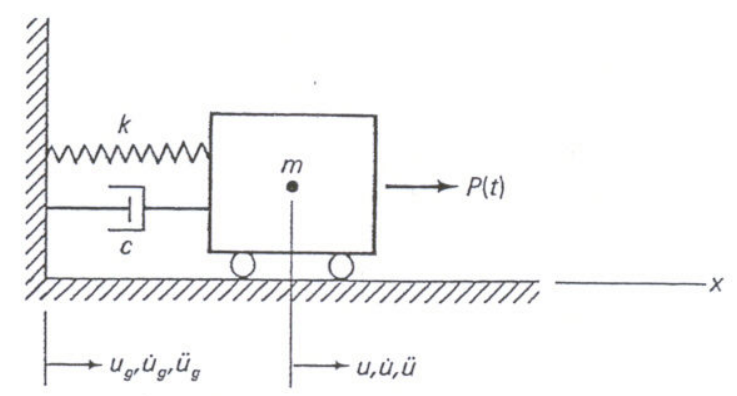

(a)

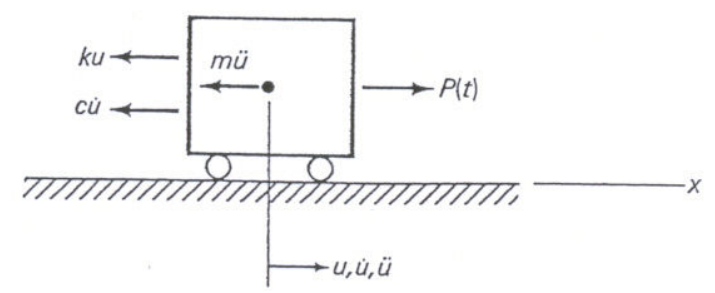

(b)

Figure 1: (a) Single Degree of Freedom (SDOF) system with viscous damping ${ }^{1}$

(b) Partial free-body diagram of the SDOF system ${ }^{1}$

The general equation of motion for a multi degree of freedom system can be expressed in matrix form as shown in equation 2.

$$
[M]\{\ddot{U}\}+[C]\{\dot{U}\}+[K]\{U\}=\{P(T)\}
$$

In equation (2), $[M]$ is the mass matrix, $[C]$ is the damping matrix and $[K]$ is the stiffness matrix. $\{P(T)\}$ is the excitation force matrix as a function of time. $\{U\},\{\dot{U}\}$ and $\{\ddot{U}\}$ are the displacement, velocity and acceleration matrices respectively. Assuming " $\mathrm{n}$ " defines the number of degrees of freedom of the vibrating system, the size for matrices $[M],[C]$ and $[K]$ are (n $\mathrm{n} \mathrm{n}$ ), and the size for matrices $\{U\},\{\dot{U}\},\{\ddot{U}\}$ and $\{P(T)\}$ are (n x 1). 
By using the principle of virtual work, one can model a vibrating system in terms of finite elements and develop equations of motion for the finite elements in the format of equation (2). ${ }^{2}$ The degrees of freedom for the finite element formulation can be either displacement or rotation at the finite element nodes. ${ }^{2}$

The finite element equations include energy-equivalent mass, damping, stiffness and nodal forces for a typical finite element. ${ }^{2}$ The finite element modeling is usually done by using a commercially available software. However, the user must have an understanding of the underlying principles in order to use the software correctly. The correct use of software involves selecting the proper elements for the problem under study, choosing the correct boundary conditions, applying the correct forces and boundary conditions to the structure, and meshing the model correctly. Figure 2 shows examples of structures modeled by the finite element technique. $^{3}$

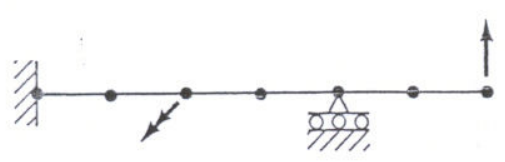

(a)

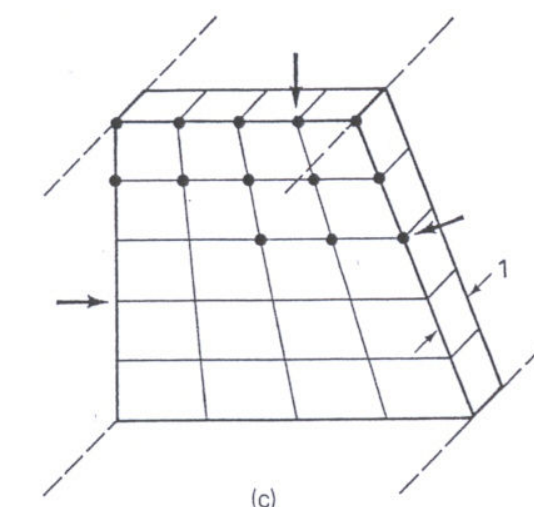

(c)

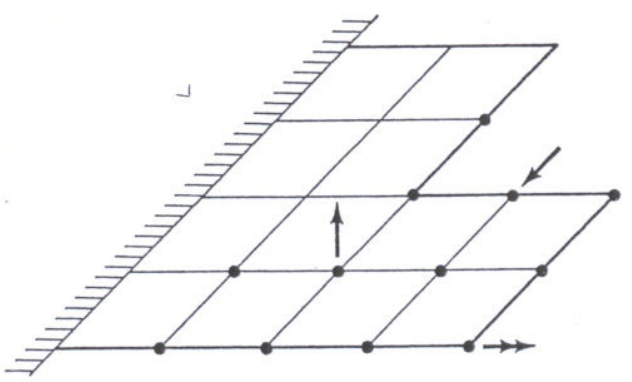

(e)
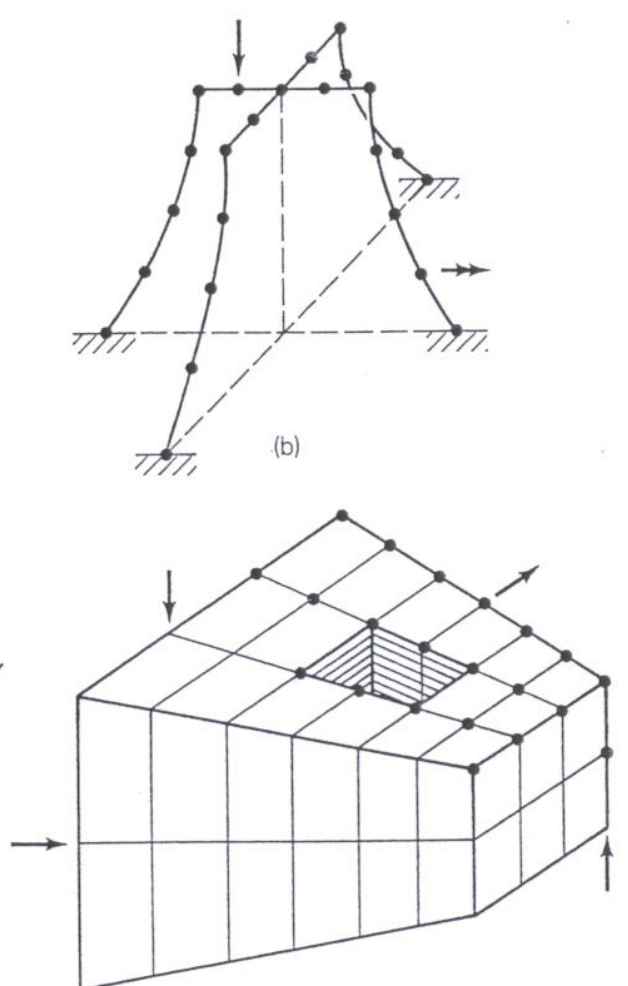

(d)

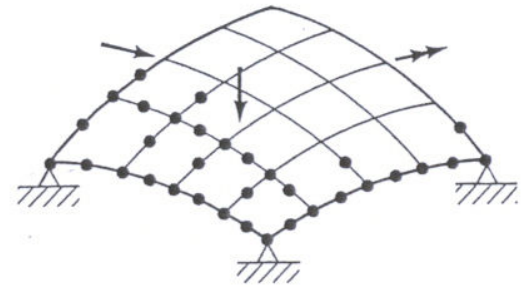

(f)

Figure 2: Structures modeled by finite elements: (a) beam ${ }^{3}$; (b) space frame ${ }^{3}$ (c) $\operatorname{solid}^{3}$, (d) solid $^{3}$, (e) plate ${ }^{3}$, (f) shell ${ }^{3}$ 


\title{
III: Description of ANSYS elements used in the examples of sections IV, V and VI
}

ANSYS is a commercially available finite element software package. There are many element types available in ANSYS. The following is a description of the ANSYS elements used in the examples in this article.

\begin{abstract}
ANSYS BEAM3 element ${ }^{4}$
ANSYS BEAM3 element is a uniaxial element with tension, compression and bending capabilities. The element has three degrees of freedom at each node, namely, translations in the nodal $x$ and $y$ directions and rotation about the nodal Z-axis. Figure 3 shows the geometry, node locations, and the coordinate system for the element. The element is defined by two nodes, the cross sectional area, the area moment of inertia, the height, and the material properties.
\end{abstract}

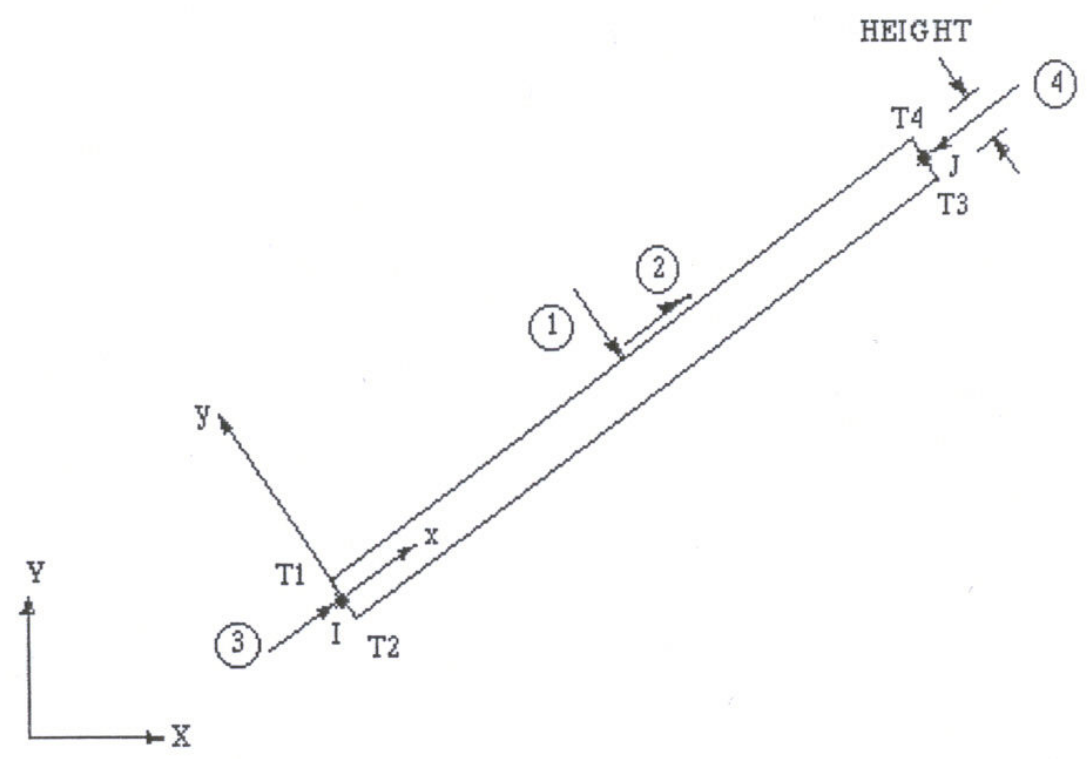

Figure 3: ANSYS BEAM3, 2-D elastic beam element ${ }^{4}$

\section{ANSYS COMBIN14 element ${ }^{5}$}

ANSYS COMBIN14 element has longitudinal or torsional capability in one, two, or three dimensional applications. The longitudinal spring-damper option is a uniaxial tensioncompression element with up to three degrees of freedom at each node, namely, translations in the nodal $\mathrm{x}, \mathrm{y}$, and $\mathrm{z}$ directions. No bending or torsion is considered. The torsional spring-damper option is a purely rotational element with three degrees of freedom at each node, namely, rotations about the nodal $\mathrm{x}, \mathrm{y}$, and $\mathrm{z}$ axes. No bending or axial loads are considered. The springdamper has no mass. Masses can be added by using the ANSYS MASS21 element. The spring or damping capability may be removed from the element.

The geometry, node locations and the coordinate system for the element are shown in Fig. 4. The element is defined by two nodes, a spring constant and two damping coefficients. The damping capability is not used for undamped modal analysis. 


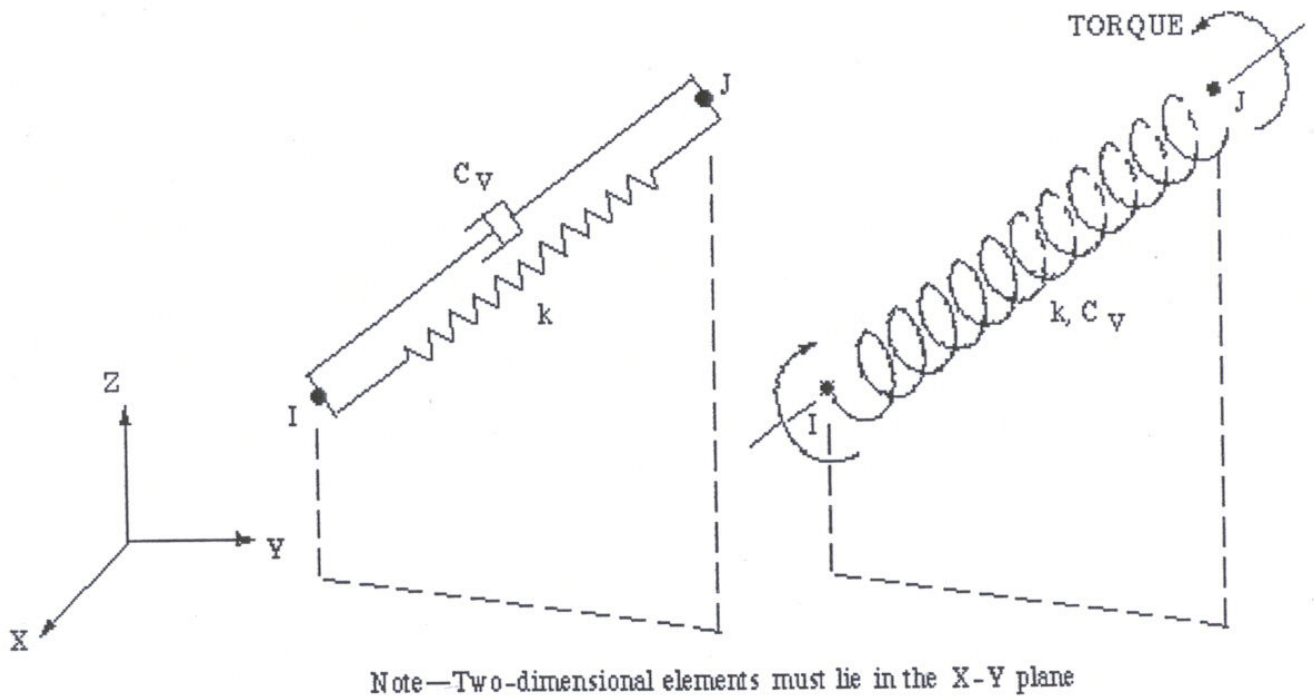

Figure 4: ANSYS COMBIN14, Spring-Damper element ${ }^{5}$

\section{ANSYS MASS21 element ${ }^{6}$}

ANSYS MASS2 1 element is a point element having up to six degrees of freedom, namely translations in the nodal $\mathrm{x}, \mathrm{y}$ and $\mathrm{z}$ directions, and rotations about the nodal $\mathrm{x}, \mathrm{y}$ and $\mathrm{z}$ axes. A different mass and rotary inertia may be assigned to each coordinate direction.

The mass element is defined by a single node as shown in Fig. 5.

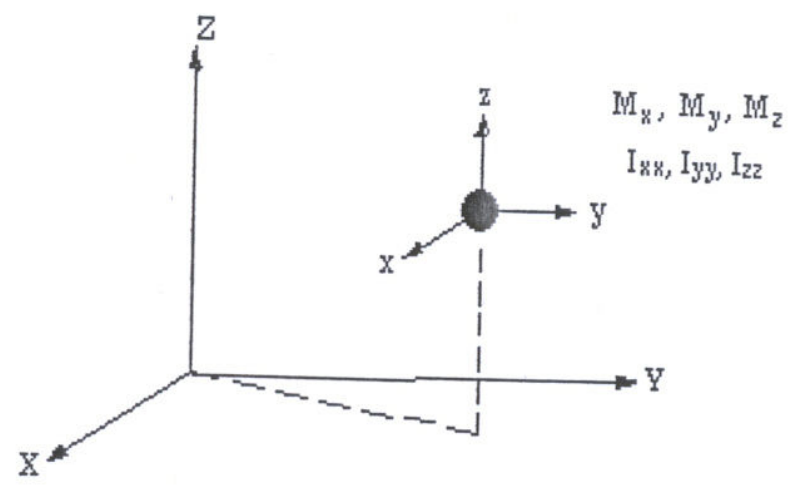

Figure 5: ANSYS MASS21 element ${ }^{6}$

\section{ANSYS SOLID45 element ${ }^{7}$}

SOLID45 is used for the three dimensional modeling of solid structures. The element is defined by eight nodes having three degrees of freedom at each node, namely, translations in the nodal $\mathrm{x}$, $\mathrm{y}$ and $\mathrm{z}$ directions. The geometry, node locations, and the coordinate system for this element are shown in Fig. 6. The element input data include the location of the nodes, and material properties. 

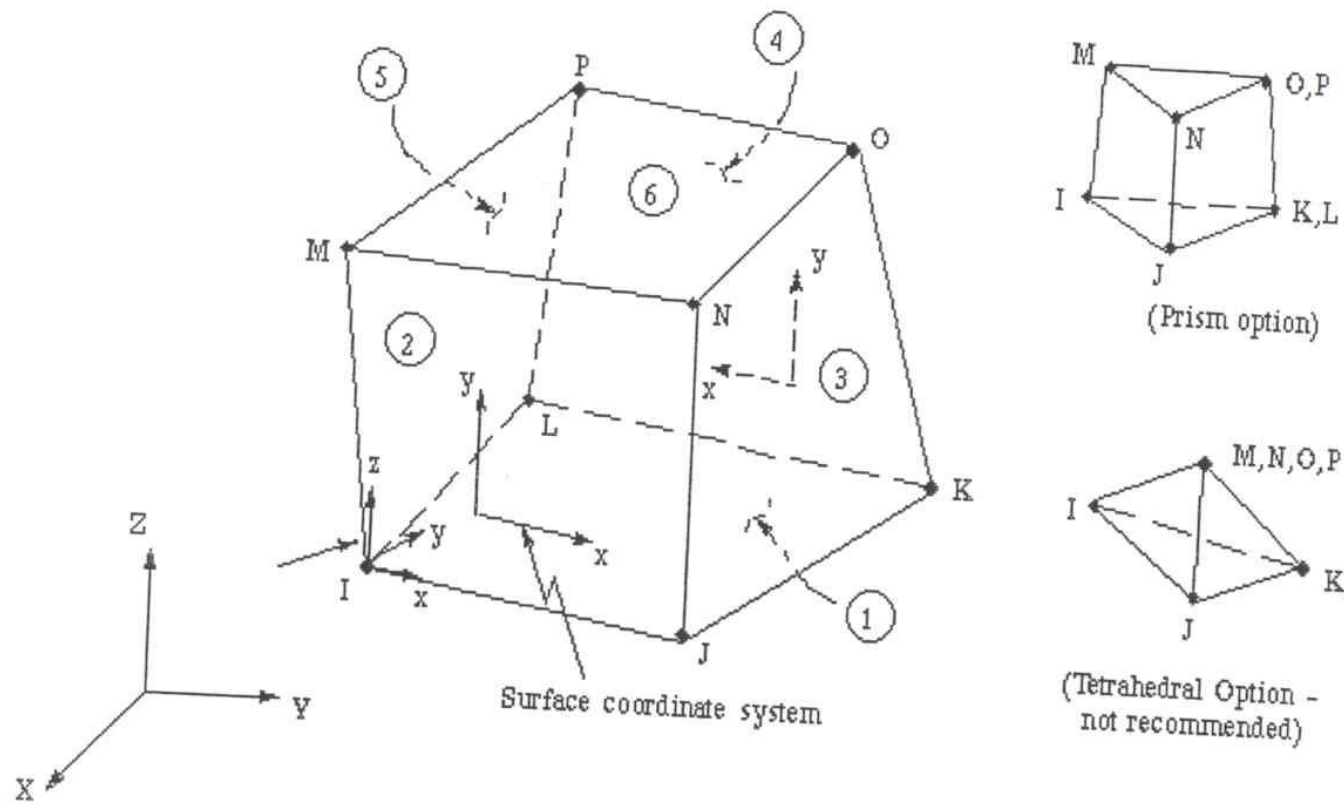

(Prism option)

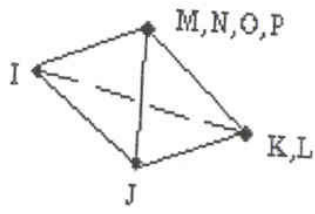

(Tetrahedral Option not recommended)

Figure 6: ANSYS SOLID45, 3-D structural solid element ${ }^{7}$

\section{IV: A Modal Analysis Example}

Modal analysis is used for determining the natural frequencies and mode shapes of a structure. Consider equation (2). If the damping matrix $[\mathrm{C}]$ and the excitation force matrix $\{P(T)\}$ are set to zero in equation (2), then equation (3) is obtained.

$[M]\{\ddot{U}\}+[K]\{U\}=\{0\}$

If equation (3) is multiplied by the inverse of matrix $[M]$, namely $[M]^{-1}$, then the following equation (4) is obtained. ${ }^{8}$

$[I][\ddot{U}]+[A][U]=\{0\}$

Where $[I]$ is a unit matrix, and $[A]=[M]^{-1}[K]$.

Matrix $[A]$ is referred to as the system matrix. Assuming harmonic motion, equation (5) is obtained.

$[\ddot{U}]=-\{\lambda\}\{U\}$

$\{\lambda\}$ is related to the system natural frequencies by equation (6).

$\{\lambda\}=\left\{\omega^{2}\right\}$

Substituting in equation (4) results in equation (7).

$\{[A]-\{\lambda\}[I]\}\{U\}=0$

Proceedings of the 2004 American Society for Engineering Education Annual Conference \& Exposition Copyright (C)2004, American Society for Engineering Education 
The characteristic equation of the system is the determinant of matrix $\{[A]-\{\lambda\}[I]\}$ set to zero. The roots of the characteristic equations are the natural frequencies of the system raised to the power of two. By substituting the $\lambda$ values into equation (7), the mode shapes of the system are determined.

ANSYS structural analysis guide contains a Modal analysis example of a model plane wing fixed at one end. ${ }^{9}$

Figure 7 shows the geometry and material properties for the wing.

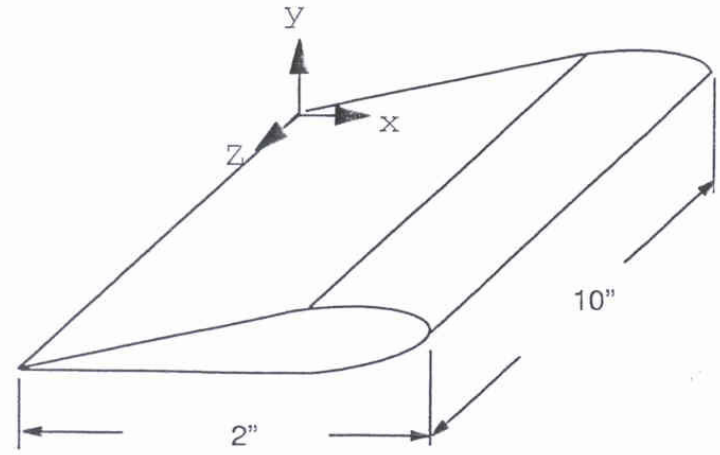

Young's modulus $=38 \times 10^{3} \mathrm{psi}$

Poisson's ration $=.3$

Density $=1.033 \mathrm{e}-3$ slugs $/ \mathrm{in}^{3}$

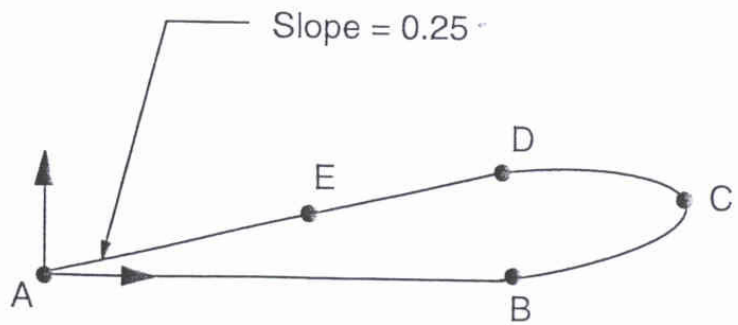

$\mathrm{B}(2,0,0)$

C $(2.3, .2,0)$

$\mathrm{D}(1.9, .45,0)$

$\mathrm{E}(1, .25,0)$

Figure 7: Geometry and material properties for

The model plane wing ${ }^{9}$

Figure 8 shows the ANSYS finite element model of the wing. The wing is modeled as being fixed at one end. ANSYS SOLID45 elements are used for modeling the wing.

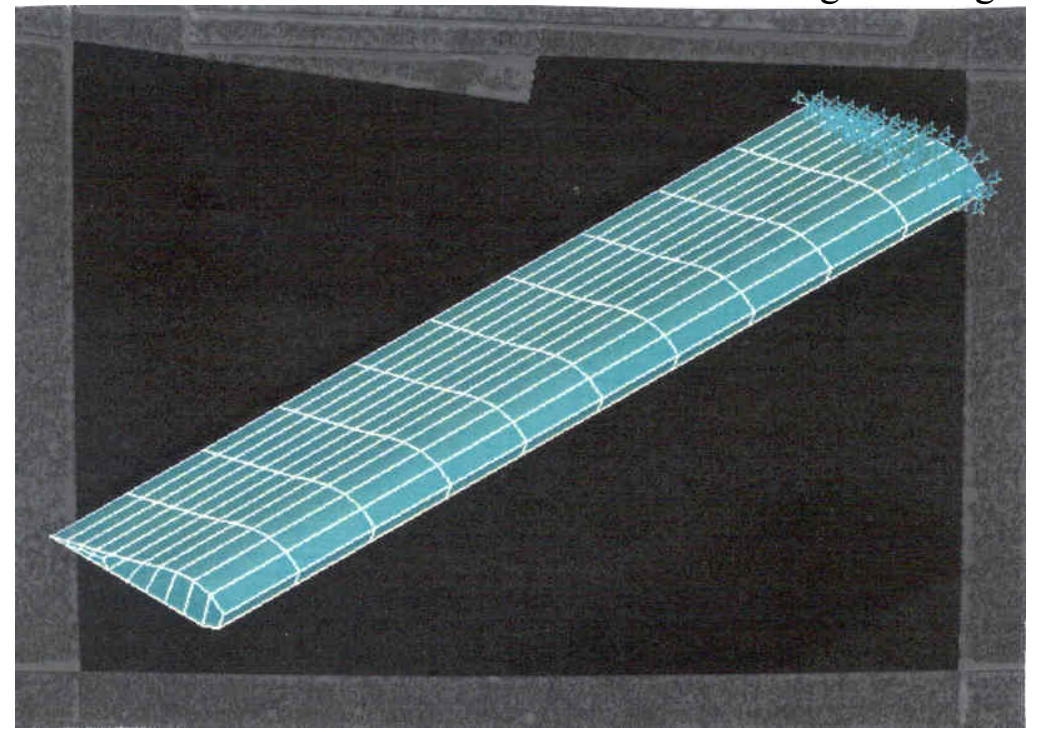

Figure 8: ANSYS finite element model of a model plane wing, fixed at one end. 
The first five modes of the structure are calculated. The natural frequencies for modes 1 through 5 are calculated to be $(3.6 \mathrm{~Hz}, 17.2 \mathrm{~Hz}, 22.9 \mathrm{~Hz}, 36.4 \mathrm{~Hz}$ and $65.9 \mathrm{~Hz})$. The ANSYS software produces mode shapes for all the available modes. To illustrate the concept of mode shapes, the mode shape for mode 5 is shown in Fig. 9.

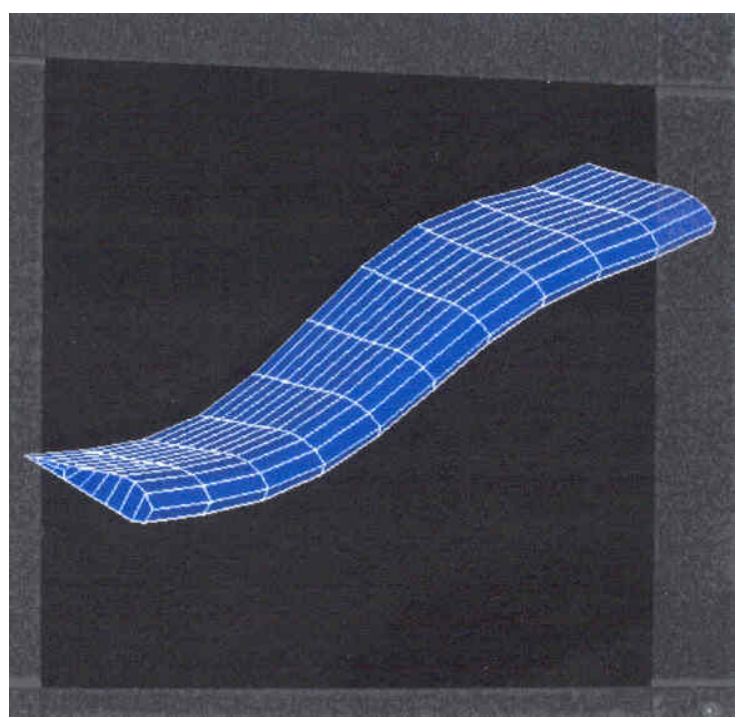

Figure 9: Mode shape 5 for the model plane wing.

\section{V: A Harmonic Response Analysis Example}

Harmonic response analysis is a technique used for determining the steady-state response of a structure to loads that vary sinusoidally (harmonically) with time. Any sustained cyclic load will produce a sustained cyclic response. Harmonic response analysis provides the ability to predict the sustained dynamic behavior of a structure, thus enabling one to verify whether or not a design will successfully overcome resonance, fatigue, and other harmful effects of forced vibrations. ${ }^{10}$

The harmonic response analysis technique only calculates the steady-state, forced vibrations of a structure. The transient vibrations, which occur at the beginning of the excitation, are not accounted for in a harmonic response analysis. Figure 10 shows a typical harmonic response system. In Fig. 10, $\mathrm{F}_{0}$ and $\omega$ are known. $\mathrm{u}_{0}$ and $\Phi$ are unknown. Part (b)of Fig. 10 is an illustration of the transient and steady-state dynamic response of a structure. ${ }^{10}$
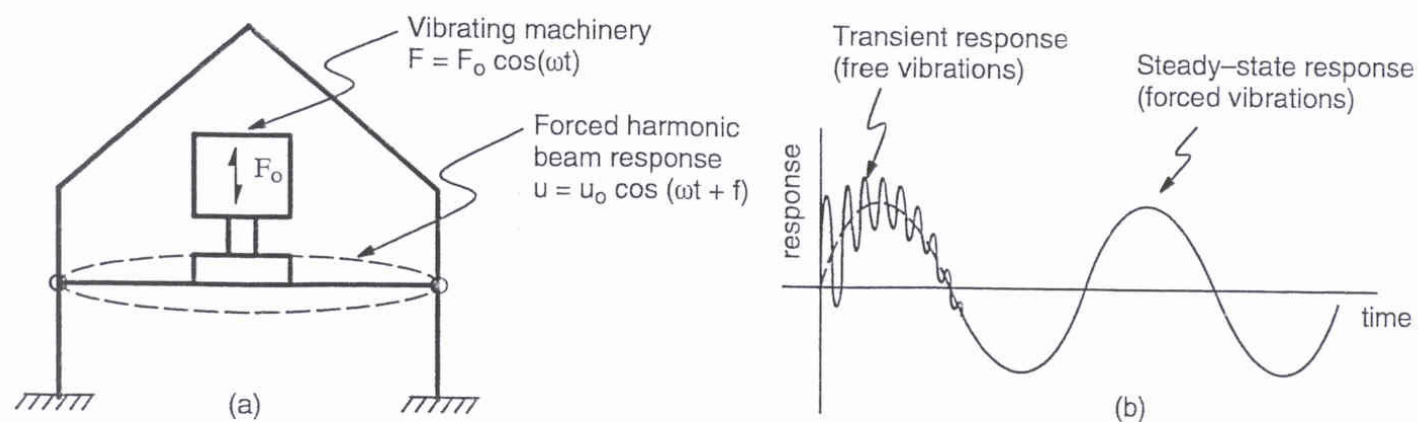

Figure 10: A typical harmonic response system ${ }^{10}$ 
Figure 11 is a sketch for a problem to be solved by the ANSYS finite element software. ${ }^{10}$ Material properties to be used for the model of Fig. 11 are $\mathrm{m}_{1}=\mathrm{m}_{2}=0.5 \mathrm{lb}-\mathrm{sec}^{2} / \mathrm{in}$, and $\mathrm{k}_{1}=\mathrm{k}_{2}=$ $200 \mathrm{lb} / \mathrm{in}$. The spring lengths are arbitrarily selected and are used only to define the spring direction. Two master degrees of freedom are selected at the masses in the spring direction. A frequency range of zero to $7.5 \mathrm{~Hz}$ with a solution at $7.5 / 30=0.25 \mathrm{~Hz}$ intervals is chosen to give an adequate response curve. The ANSYS COMBIN14 element is used for modeling the system. Figure 12 shows the representative finite element model. ${ }^{10}$

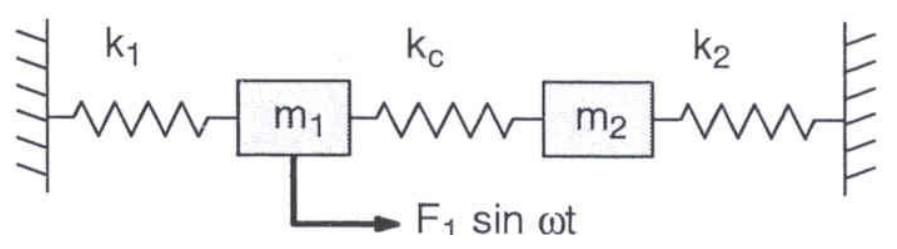

Figure 11: Sketch of the system for the example harmonic response analysis ${ }^{10}$

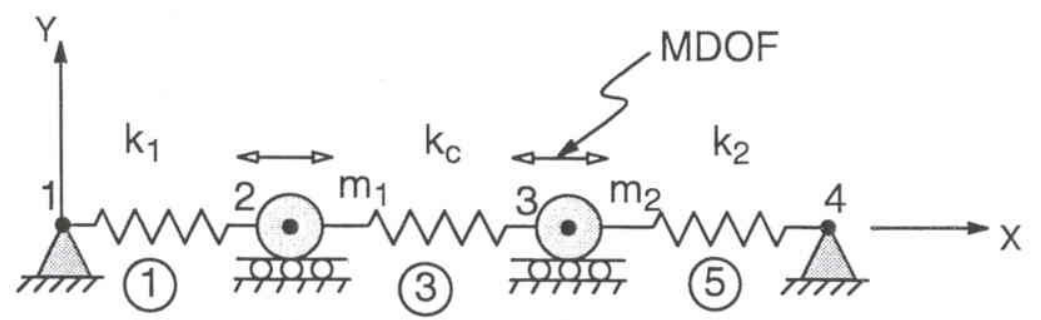

(2)

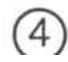

Figure 12: Representative finite element model of system shown in Fig. $11^{10}$

Figure 13 is the harmonic response of the system shown in Fig. 11. ${ }^{10}$

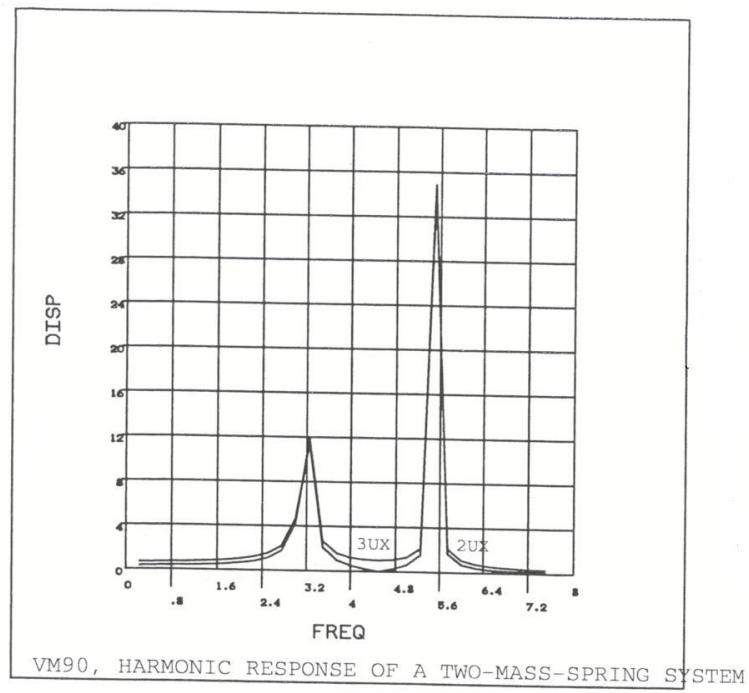

Figure 13: Amplitude vs. Frequency plot showing the response for the system of Fig. $11^{10}$ 
For this particular harmonic analysis example, no damping component was defined for the COMBIN14 element. Therefore, the $[C]$ component of equation (2) had no part in the solution. Most harmonic analyses are conducted by ignoring the damping effects of the structure. However, the damping effects become an important consideration when the frequency of the forcing function is close to one of the natural frequencies of the structure. ANSYS allows for the damping effects to be included in an analysis.

\section{VI: A Transient Dynamic Analysis Example}

Transient dynamic analysis (also called time-history analysis) is a technique used to determine response of a structure under the action of any general time-dependent load. This kind of analysis can be used to determine the time-varying displacements, strains, stresses, and forces in a structure as it responds to any combination of static, transient, and harmonic loads. The time scale of the loading is such that the inertia and/or damping effects are considered to be important. ${ }^{11}$

Equation (2) is the basic equation that is solved by a transient dynamic analysis. At any given time, $t$, these equations can be thought of as a set of "static" equilibrium equations that also take into account inertia forces $([M][\ddot{U}])$ and damping effects $([C][\dot{U}])$. The ANSYS software solves these equations at discrete time points, using the solution of one time step as the initial condition for the next time step. ${ }^{11}$

ANSYS structural analysis guide presents an example of a transient dynamic analysis problem. ${ }^{11}$ The following is the problem description.

A steel beam of length $l=20 \mathrm{ft}$ and, modulus of elasticity $\mathrm{E}=30000 \mathrm{ksi}$, mass and moment of inertia $\mathrm{I}=800.6 \mathrm{in}^{4}$ is supporting a concentrated mass $\mathrm{m}=0.0259076 \mathrm{kips}_{-} \mathrm{sec}^{2} / \mathrm{in}$ as shown in Fig. 14. As shown on Fig. 14, the beam is subjected to a dynamic load $F(t)$. Figure 15 is the time history for $\mathrm{F}(\mathrm{t})$.

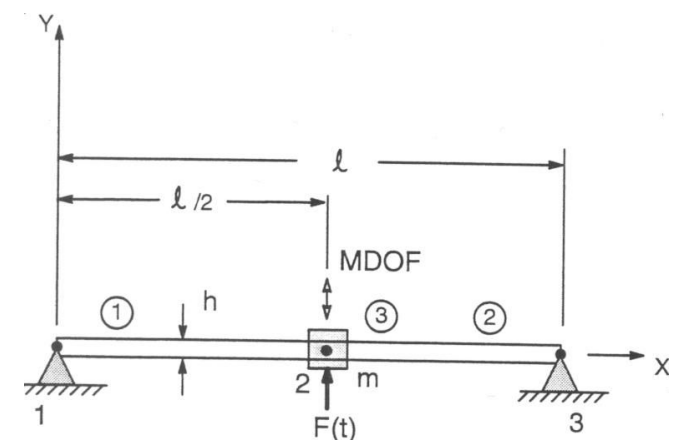

Figure 14: Transient Dynamic Analysis Model ${ }^{11}$ 


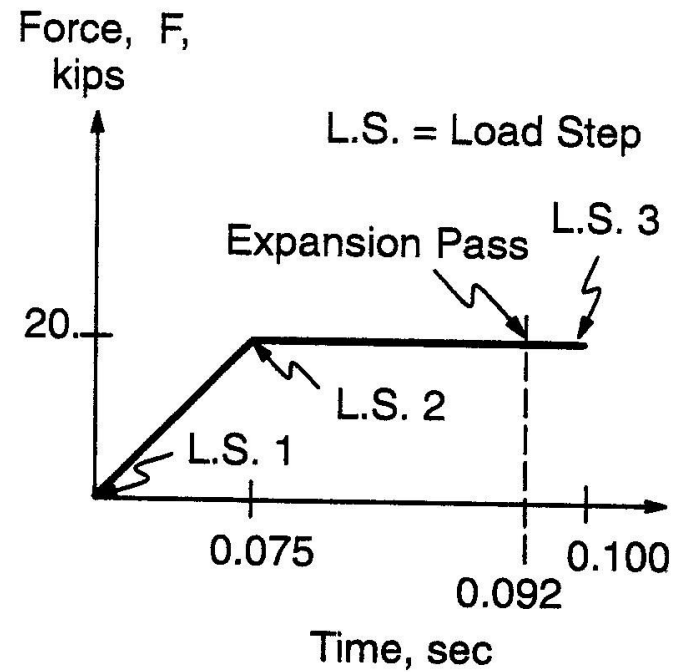

Figure 15: Force time history of $F(t)$ applied to the model shown in Fig. $14^{11}$

The problem is determining the time of maximum displacement response and the maximum response. The responses are to be determined ignoring the weight of the beam. ANSYS BEAM3 and ANSYS MASS21 finite elements are used for modeling the system.

Figure 16 is the ANSYS results after the system of Fig. 14 was modeled, and the load shown in Fig. 15 was applied to the model and the solution was obtained. As it is indicated in Fig. 16, the time of maximum displacement is .092 second after the initiation of loading, and the maximum displacement is .33 inch.

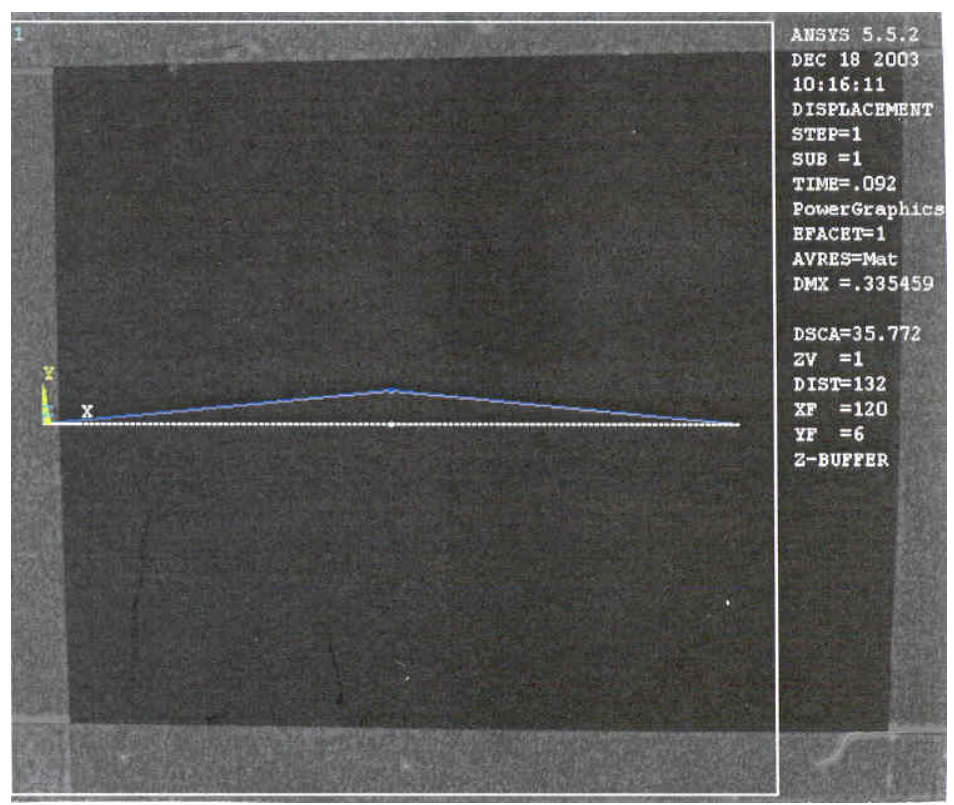

Figure 16: ANSYS results for the model of Fig. 14 with the force input of Fig. 15. 


\section{VII: Educational Benefits of Including Finite Element In A Vibration Analysis Curriculum}

The finite element technique can be used as a tool to perform quick parametric studies of how different variables affect the vibration characteristics of a system. This will help the students to quickly analyze different scenarios, and there by improve their understanding of the fundamental concepts taught in a typical vibration course. This outcome will be of special benefit to students in an intermediate undergraduate course.

The technique is also necessary for an accurate analysis of most real world engineering problems, and is in wide use in a variety of industries. An in depth coverage of the finite element technique as it relates to vibration analysis will enable the students to be better prepared to meet their real world engineering challenges. An in depth coverage of the technique can be accomplished by having an independent course that is focused on the use of finite element modeling in vibration analysis. Such a course can be offered as an advanced undergraduate or a introductory graduate level course.

\section{VIII: Summary and Conclusion}

This article presents the use of the ANSYS finite element software as a supplemental teaching tool in a vibration analysis curriculum. The article also emphasizes that in order to use the ANSYS software correctly, a thorough understanding of the underlying concepts of vibration analysis is required.

The article points out the use of finite element technique as a supplemental rather than a substitute for classical vibration analysis. Included are three analyses - modal, harmonic and transient dynamic as examples of problems solved by ANSYS finite element software.

Suggestions for including the finite element analysis techniques at an undergraduate and a graduate level vibration analysis curriculum are made.

\section{Bibliography}

[1] Structural Dynamics by Finite Elements by Weaver \& Johnson, page 26.

[2] Structural Dynamics by Finite Elements by Weaver \& Johnson, page 78.

[3] Structural Dynamics by Finite Elements by Weaver \& Johnson, page 74.

[4] ANSYS elements manual, section 4.3.

[5] ANSYS elements manual, section 4.14.

[6] ANSYS elements manual, section 4.21.

[7] ANSYS elements manual, section 4.45.

[8] Theory of Vibration With Applications, Third Edition, by William T. Thomas, page 165

[9] ANSYS structural analysis guide, chapter 3.

[10] ANSYS structural analysis guide, chapter 4.

[11] ANSYS structural analysis guide, chapter 5.

\section{Cyrus K. Hagigat}

Dr. Hagigat is an assistant professor of engineering technology at the Engineering Technology Department of The University of Toledo. He is currently teaching both campus and distance learning courses. He is involved in developing new distance learning courses for an engineering technology masters degree program at The University of Toledo. He is a registered Professional Engineer in State of Ohio. 